\title{
First-time versus repeat visitors at the Kruger National Park
}

\begin{abstract}
Authors:
Martinette Kruger Melville Saayman ${ }^{1}$ Uwe P. Hermann²

Affiliations:

${ }^{1}$ Tourism Research in Economic Environs and Society (TREES), North-West University, South Africa

${ }^{2}$ Department of Tourism Management, Tshwane University of Technology, South Africa

\section{Correspondence to:} Martinette Kruger

\section{Email:}

martinette.kruger@nwu. ac.za

\section{Postal address:}

PO Box 204, Potchefstroom

2520, South Africa

Dates:

Received: 08 Aug. 2013

Accepted: 06 Sept. 2013

Published: 10 July 2014

How to cite this article: Kruger, M., Saayman, M. \& Hermann, U.P., 2014, 'Firsttime versus repeat visitors at the Kruger National Park', Acta Commercii 14(1), Art. \#220, 9 pages. http://dx.doi. org/10.4102/ac.v14i1.220
\end{abstract}

\section{Note:}

This article's research is based on work previously published by the author.

\section{Copyright:}

(C) 2014. The Authors. Licensee: AOSIS OpenJournals. This work is licensed under the Creative Commons Attribution License.
Purpose: The aim of this research is to segment visitors at the Kruger National Park based on the frequency of visitation in order to distinguish between first-time and repeat park visitors.

Problem investigated: The Kruger National Park (KNP) in South Africa is one of the world's most renowned wildlife reserves. The KNP is in great demand because it is regarded as an all-inclusive holiday destination that provides tourists with a unique nature and leisure experience. As a result, the park attracts over one million visitors per annum and is one of the top five international tourist destinations in the country. For the KNP to sustain its visitor numbers, park managers should realise that both first-time and repeat visitor groups play a fundamental role in the overall competitiveness and success of the park, and they should strive to achieve a balance between first-time and repeat visitors. Therefore, the park management should know which attributes of the park attract first-time visitors group and which attract repeat visitors.

Design and methodology and approach: A research survey was done at various rest camps in the KNP from 26 December 2010 to 03 January 2011; a total of 436 visitor questionnaires were completed. Two-way frequency tables and chi-square tests as well as analysis of variance and Tukey's multiple comparisons were used to analyse the data and segment first-time and repeat visitors based on socio-demographics and behavioural characteristics as well as travel motivations.

Findings and implications: The results indicated that first-time visitors are long-haul visitors, are younger and pay for fewer people whilst repeat visitors are mainly motivated by escape and plan their trips well in advance. These differences indicate that the KNP should follow a twopronged marketing approach aimed at both visitor markets. This would greatly contribute to the long-term sustainability and competitiveness of the KNP.

\section{Introduction}

Visitors to a destination, including national parks, comprise both first-timers and repeaters. Firsttime visitors could be associated with a 'new' market and are those visitors who are visiting the destination for the first time (Um, Chon \& Ro 2006). Repeat visitors can be seen as an established customer base and are visitors who have visited the destination more than once (Kerstetter \& Cho 2004; Um et al. 2006). According to Oppermann (2000), Petrick, Morais and Norman (2001) and Vogt, Stewart and Fesenmaier (1998), both the abovementioned visitor groups play a fundamental role in ensuring that an attraction or a destination (such as a national park) sustains its visitor numbers, its overall competitiveness and ultimately its success. Park managers should therefore strive to achieve a balance between first-time and repeat visitors. This is imperative, in view of the economic impact of national parks, especially in South Africa, and the consequent benefits of attracting and retaining visitors. South Africa has in excess of 20 national parks and in addition to this there are many local and provincial parks and a further 9000 privately owned game reserves competing for ecotourists (Saayman \& Van der Merwe 2004). Neighbouring countries such as Namibia, Zimbabwe and Botswana are also very competitive and, according to Saayman (2003), it has therefore become crucial for national parks to keep up with trends and the needs of tourists, since this would streamline future marketing strategies. Shanka and Taylor (2004:135) add that, whereas many tourism operations, including national parks, rely on repeat visitors, it is worthwhile determining which of the attributes significantly attract first-time visitors and which appeal to repeat visitor groups, because these findings could be beneficial to the organisation (park) management in terms of effectively marketing the park and gaining a competitive advantage as well as ensuring the long-term sustainability of the park.

\section{Theoretical background}

According to Petrick (2004), increasing numbers of first-time visitors are associated with market growth; however, the creation of a new market is seen by some as being associated with increased 
costs, since establishing a new market requires a significant deployment of resources. Losing existing visitors is also associated with higher marketing costs (Kotler, Bowen \& Makens 2003:395); therefore, it is equally important to retain visitors. This is because an established market provides the supplier with a cost advantage, as fewer resources are needed to maintain a market than to create a new market ( $\mathrm{Li}$ et al. 2008:297). In addition, repeat visitors provide the supplier with an indicator of service quality or service satisfaction (McCain, Jang \& Hu 2005:465-472), since repeat visitation is associated with loyalty (Kumar \& Shah 2004:317). Hellier et al. (2003) add that repeat visitors provide an additional marketing advantage, as they are the ideal conveyors of word-of-mouth promotion.

However, although repeat visitors have marketing and cost advantages for a destination, they should not be seen as the only desirable market group (Oppermann 1998; Petrick 2004). Jang and Feng (2007:587), Kruger and Saayman (2009), Li et al. (2008:279), Oppermann (1999) and Wang (2004:115) therefore suggest that it is very important to distinguish between first-time and repeat visitors, since the tourism demand of repeat visitors is quite different from that of first-time visitors. Managers should distinguish between the two groups of visitors and plan their marketing strategies accordingly (Correia, Oliveira \& Butler 2008:198; Lau \& McKercher 2004:285). If a destination focuses on one group only, it might result in a misunderstanding of market movement and the ineffective allocation of resources (Jang \& Feng 2007:587). An understanding of both visitor groups would provide destination marketers with a more specific direction (Li et al. 2008:279) and a greater ability to adapt to a continuously changing environment (Chiang, Wang \& Chen 2010:757). Travel and destination (park) managers therefore need to consider these differences and to propose different programmes for these two potentially different market segments (Vogt et al. 1998:69; Wang 2004:115). In particular, information concerning tourists' status as first-time or repeat visitors could be useful in market segmentation (Formica \& Uysal 1995), signalling destination familiarity (Tideswell \& Faulkner 1999) and determining a park's position in its life cycle (Oppermann 1998:136; Priestly \& Mundet 1998). The appropriate management combination of first-timers and repeat visitors could thus ultimately contribute to greater sustainability (Kruger \& Saayman 2009).

Li et al. (2008:278) state that most tourism researchers report differences between first-time and repeat visitors in terms of demographics, destination perception, perceived value and travel motivations. Although a number of research papers have focused on the topic of differentiation between first-time and repeat visitors, the existing literature still paints a mixed picture and does not provide the needed clarity. With regard to socio-demographic differences between first-timers and repeaters, the findings are as follows: first-time visitors tend to be younger compared to repeaters (Gitelson \& Crompton 1984:1999; Kruger \& Saayman 2009; Kruger, Saayman \& Ellis 2010:95; Lau \& McKercher 2004; Li et al. 2008; Shani, Rivera \& Hara 2009:99). First-time visitors also stay at a destination for a shorter time than repeat visitors do (Kruger et al. 2010; Lau \& McKercher 2004; Oppermann 1997:179; Wang 2004). However, this is contradicted by a finding by Kruger and Saayman (2009) and Li et al. (2008:289), who have observed that first-timers stayed longer at a destination compared to repeaters. Kruger and Saayman (2009) also noted that firsttime visitors usually have more money and as a consequence they spend more money. This corresponds to findings by Alegre and Juaneda (2006:686), Kruger et al. (2010), Li et al. (2008:288), Oppermann (1997:178), Petrick (2004:469) and Tang and Turco (2001:39). Shani et al. (2009:99) and Wang (2004:108), on the other hand, have found that repeat visitors tend to fall in the higher income class and therefore exhibit higher levels of spending.

With regard to trip preferences, travel motives and activities sought, Kruger et al. (2010) and Li et al. (2008:288) found that first-time visitors are more likely to be long-haul visitors who travel longer distances, whilst repeaters tend to travel to visit friends and relatives and take weekend trips. This contradicts the findings of Shani et al. (2009:99), who state that repeat visitors tend to travel further whilst local residents also tend to be repeaters. The ability to socialise is a major factor for repeat visitors, whilst first-time visitors are motivated more by curiosity (Crompton et al. 1992:366). Gitelson and Crompton (1984), Hughes and Morrison-Saunders (2002) and Kruger et al. (2010) found that first-timers tend to seek variety and new cultural experiences, whilst returning visitors are more likely to be seeking relaxation and spending time with or visiting family and friends. First-time visitors are involved in more activities and explore a destination more widely, with a specific interest in large icons and events (Crompton et al. 1992:366; 2004:159; Lau \& McKercher 2004:284; Wang 2004:108), whilst repeaters spend their time more intensively, engage in activities related to local culture and life, prefer participating in more social activities such as shopping, dining or visiting friends and relatives, and are destination-aware visitors who are knowledgeable regarding the range of activities available (Lau \& McKercher 2004:279; Li et al. 2008:280; Oppermann 1997:178; Wang 2004:108). The latter observation is supported by Hong et al. (2009:286), Lehto, O'Leary and Morrison (2004), Morais and Lin (2010:206), Oppermann (1997) and Shanka and Taylor (2004:142), as well as Reid and Reid (1993), who found that repeat visitors make use of a wide range of independent or external information sources (especially radio and newspapers) and past experience as a base for their buying behaviour, compared to first-timers who rely greatly on word-of-mouth marketing channels and the internet (Kruger \& Saayman 2009; Kruger et al. 2010; Shani et al. 2009:99). Furthermore, Li et al. (2008:288) found that first-time visitors are active travel planners and start collecting information early, which contradicts the findings of Kruger et al. (2010), who state that repeat visitors plan their visits well in advance. However, Kruger et al. also found that first-timers also plan in advance, but sometimes tend to decide spontaneously.

In terms of destination perception and intention to revisit, Morais and Lin (2010:193), in a study of a destinations 
perception amongst tourists in Taiwan, found that firsttime visitors are attracted to the destination as a result of image, as opposed to repeat visitors, who return as a result of their attachment to the destination. Fakeye and Crompton (1991) found that natural and cultural amenities and accommodation are important image components for first-time visitors, whilst social factors such as food, friendly people, bars and evening entertainment are more important to repeaters. Repeat visitors are less likely to be satisfied, due to higher expectations, but have a stronger intention to return in the future (Juaneda 1996; Kruger et al. 2010; McKercher \& Wong 2004; Petrick \& Backman 2002; Shani et al. 2009:99).

The above literature analysis regarding first-time and repeat visitors shows that the findings contradict one another and that there is no clear difference between the two groups. The existing literature focuses primarily on visitation patterns and tends to emphasise destinations, events and historical sites. However, very little literature is available on the differences between first-time and repeat visitors to parks and nature-based areas, and specifically to national parks in South Africa. Since the differences between first-time and repeat visitors are not set in stone, it can be assumed that a study of the characteristics of these two visitor groups at the KNP will provide new and unique insights into the underlying differences between first-time and repeat visitors to the park.

The studies discussed in the literature review furthermore collectively concluded that destination marketers should follow a two-pronged marketing approach, considering both groups of visitors as important for the sustainability of the product or destination (Kruger et al. 2010). It is also evident from the results that the unique nature of each tourism product or destination plays a vital role in the type of visitors attracted to the destination and one can therefore not assume that these two visitor segments are homogeneous in terms of their profiles, motives, preferences and consequent behaviour at the KNP. The latter was somewhat verified by Kruger and Saayman (2010) in their comparative study of visitors' travel motives for visiting the KNP and the Tsitsikamma National Park (TNP). The results showed that visitors to these parks are motivated by a diverse set of motives (knowledge seeking, activities, park attributes, nostalgia, novelty and escape and relaxation for the KNP; knowledge seeking, nature experience, photography, escape and relaxation, park attributes and nostalgia for the TNP). However, the differences between first-time and repeat visitors to the KNP or any other South African national park have not yet been established.

Based on this, Lau and McKercher (2004:284) emphasise that tourism destinations such as the KNP should achieve a balance between first-time and repeat visitors, and that the generation of repeat visitation relies on the ability of the park to successfully convert first-time users into returning visitors (Kruger \& Saayman 2009). This requires developing a comprehensive understanding of the reasons why both visitor segments come to the park and what the visitors comprising each group prefer to do during their stay (Lau \& McKercher 2004:285). Hence, it is imperative to assess the viability of first-time and repeat visitors by distinguishing between these two visitor groups at the KNP.

\section{Purpose and objectives}

The aim of this research is to segment visitors at one of the oldest and most profitable national parks in South Africa and in the world, namely the Kruger National Park (KNP), based on the frequency of visitation, in order to distinguish between first-time and repeat visitors. The KNP is renowned for its wildlife management, which is unparalleled on the African continent, its diversity of animal species and its variety of vegetation zones (Mabunda \& Wilson 2009:117; SANParks 2009:31). This national park acts as a strong magnet for tourists, is a major export earner and constitutes an important part of the South African tourism industry (Cook, Yale \& Marqua 2010:212; Uysal, McDonald \& Martin 1994:18). The KNP is furthermore an all-inclusive holiday destination and provides tourists with a unique nature and leisure experience, which is a major attraction for both domestic and international tourists (Saayman \& Saayman 2009). The first tourists were allowed into the park in 1927 and since then the number of visitors has grown significantly: in 2009-2010 a total of 1429904 visitors visited the park (SANParks 2010:34). Based on these figures, it is not surprising that South Africa's National Parks (SANParks) currently generates $80 \%$ of its revenue from accommodation and admission fees in the KNP (Mabunda \& Wilson 2009:118).

\section{Methodology}

This research is of a quantitative nature and a structured questionnaire was used to collect the data. The method of research used will be discussed under the following headings: (1) the questionnaire, (2) sampling method and survey, and (3) statistical analysis.

\section{The questionnaire}

The questionnaire used to survey visitors was based on similar research conducted by Downward and Lumsdon (2004), Kruger et al. (2010), Leones, Colby and Crandall (1998) and Mehmetoglu (2007), and consisted of three sections. Section A captured the demographic details of the visitors (language, gender, age, race, marital status, country of residence, province, highest qualification and occupation), whilst Section B measured the economic information such as size of travel group, number of people paid for, an indication of whether visitors were visiting for the day or staying overnight, the type of accommodation they stayed in, the number of nights they stayed in the park, the number of visits over the last three years and their spending dynamics. Section $C$ measured the respondents' travel motivations for visiting the KNP. Twenty-three items were listed and respondents were asked to rate the importance of each item on a five-point Likert scale ( $1=$ not at all important; 2 = less important; 3 = important; 4 = very important; 5 = extremely 
important). For the purpose of this research, the information from all three sections was included in the analysis.

\section{Sampling method and survey}

All overnight visitors to the park in the survey period (29 December 2010 - 03 January 2011) formed part of the sample. Overnight visitors staying in chalets and in the camping area were included in the surveys. Field workers distributed questionnaires in the evenings and collected the questionnaires later in the same evening or early the next morning. According to the figures provided by SANParks, there were approximately 385000 overnight visitors at KNP during 2009. Since only one questionnaire was administered per travelling group, this total was divided by the number of people for whom visitors were financially responsible in 2010 (an average of 3.9 persons) (Kruger et al. 2010:12). This resulted in a population size of approximately 99000 . According to Israel (2009:6), for a population of $100000(N)$, 398 respondents $(n)$ is seen as representative. In total, 436 questionnaires were administrated at the KNP in 2010 and 2011. The number of completed questionnaires was thus more than the number required.

\section{Statistical analysis}

Microsoft ${ }^{\odot}$ Excel $^{\odot}$ was used for data capturing whilst SPSS (SPSS Inc. 2010) was used for the analysis of data. This study comprised three stages. Firstly, a general profile of respondents at the KNP was compiled. Secondly, a principal axis factor analysis, using an Oblimin rotation with Kaiser normalisation, was performed on 22 motivation items, to explain the variance-covariance structure of a set of variables through a few linear combinations of these variables. The Kaiser-Meyer-Olkin measure of sampling adequacy and Bartlett's Test of Sphericity was used to determine whether the covariance matrix was suitable for factor analysis. Kaiser's criteria for the extraction of all factors with eigenvalues larger than 1 were used because those criteria were considered to explain a significant amount of variation in the data. In addition, all items with a factor loading above 0.3 were considered as contributing to a factor, whereas all items with factor loadings lower than 0.3 were considered as not correlating significantly with this factor (Steyn 2000). In addition, any item that cross-loaded on two factors with factor loadings greater than 0.3 was categorised in the factor where interpretability was best. A reliability coefficient (Cronbach's alpha) was computed for each factor to estimate the internal consistency of each factor. All factors with a reliability coefficient above 0.6 were considered as acceptable in this study. The average inter-item correlations were computed as another measure of reliability. According to Clark and Watson (1995), the average inter-item correlation should lie between 0.15 and 0.55 .

Lastly, visitors were analysed based on the number of years they had visited the park. Two-way frequency tables and chi-square tests as well as analysis of variance (ANOVA) and Tukey's multiple comparisons were used to investigate any significant differences between first-time and repeat visitors. The study employed demographic variables (gender, home language, age, occupation and province of origin), behavioural variables (length of stay, expenditure, decision to visit and media usage) as motivational factors to examine whether statistically significant differences existed between the two groups. Cross-tabulations with chi-square tests were furthermore employed to profile these groups demographically. The results of the statistical analysis will be discussed in the next section.

\section{Analysis and interpretation of the findings}

This section provides an overview of the profile of the respondents (visitors to the KNP in 2010 and 2011), and discusses the results of the factor analysis (travel motives) and of the ANOVA comparisons and cross-tabulations with chi-square tests.

\section{Profile of respondents}

Table 1 shows that the majority of respondents at the KNP in 2010 and 2011 were Afrikaans-speaking, an average of 45 years old, married and travelled from either Gauteng or Mpumalanga in a $4 \times 4$ vehicle. During their stay, respondents were financially responsible for an average of three persons, they stayed an average of three nights and they spent an average of R7728.53 per trip. These visitors were loyal to the park and had visited national parks an average of three times over the preceding three years.

\section{Results of the factor analysis}

The pattern matrix of the principal axis factor analysis, using an Oblimin rotation with Kaiser normalisation, identified five motivational factors that were labelled according to similar characteristics (Table 2). These factors accounted for 63\% of the total variance. All factors had relatively high reliability coefficients, ranging from 0.50 (the lowest) to 0.89 (the highest). The average inter-item correlation coefficients, with values between 0.19 and 0.54 , also imply internal consistency for all factors. Moreover, all items loaded on a factor with a loading greater than 0.3 , and the relatively high factor loadings indicate a reasonably high correlation between the factors and their component items. The Kaiser-MeyerOlkin measure of sampling adequacy of 0.88 also indicates that patterns of correlation are relatively compact and yield

TABLE 1: Profile of Kruger National Park respondents.

\begin{tabular}{ll}
\hline Category & Response \\
\hline Home language & Afrikaans (53\%) \\
\hline Age & Average age of 45 years \\
Marital status & Married (72\%) \\
$\begin{array}{l}\text { Province of residence } \\
\text { Mode of transport }\end{array}$ & Gauteng (57\%); Mpumalanga (14\%) \\
$\begin{array}{l}\text { Number of visits to national parks over } \\
\text { three years }\end{array}$ & $4 \times 4(34 \%)$; Sedan (25\%) \\
$\begin{array}{l}\text { Average length of stay } \\
\text { Number of people paid for }\end{array}$ & Three nights \\
Average spending per trip & An average of three persons \\
\hline
\end{tabular}


distinct and reliable factors (Field 2005:640). Barlett's test of sphericity also reached statistical significance $(p<0.001)$, supporting the factorability of the correlation matrix (Pallant 2007:197).

Factor scores were calculated as the average of all items contributing to a specific factor in order to interpret them on the original five-point Likert scale of measurement. As Table 2 shows, the following motives for KNP were identified: knowledge seeking (Factor 1), park attributes (Factor 2), group affiliation (Factor 3), escape (Factor 4) and exploration (Factor 5). With a mean value of 4.37 , escape was considered the most important motive to travel to the KNP, followed by park attributes (3.72), group affiliation (3.62) and knowledge seeking (3.42). Exploration (3.06) was considered as neither an important nor a less important travel motive to travel to the KNP. In previous research, Kruger and Saayman (2010) also identified escape, park attributes and knowledge seeking as motives to visit national parks in South Africa.

\section{First-time versus repeat visitors to the Kruger National Park}

An analysis of first-timers versus repeaters in the literature review established that, on a very general level, one can divide visitors at a destination into two categories, namely first-time and repeat visitors. However, there are vast differences between repeaters. Visitors to the KNP were thus divided into three groups based on the number of times they had visited the park. First-time visitors and 'very frequenters' (four or more times) account for $28 \%$ of the respondents whilst the frequenters (two and three times) are the largest segment, with $44 \%$.

\section{Results of analysis of variance and Tukey's post hoc multiple comparisons}

ANOVAs were employed to determine the differences between first-timers and repeaters at the KNP, based on socio-demographic and behavioural characteristics as well as motivational factors. As shown in Table 4, there are statistically significant differences between first-timers and repeaters (frequent and very frequent visitors) based on age $(p=0.001)$. First-timers and frequent visitors differ statistically from very frequenters; first-timers and very frequent visitors are younger (an average of respectively 42 and 45 years) compared to very frequenters who are an average of 50 years old.

Group size ( $p=0.092)$ and the travel motives knowledge seeking $(p=0.091)$ and exploration $(p=0.073)$ were also significant at a $10 \%$ level of significance; however, Tukey's post hoc multiple comparisons showed no statistical significance. There are furthermore no statistically significant differences between first-timers and repeaters based on length of stay $(p=0.365)$ and expenditure per person $(p=0.259)$. Also, no statistically significant differences existed between the visitor groups based on the other motivational factors. Based on the results,

TABLE 2: Results of factor analysis of Kruger National Park visitor motives.

\begin{tabular}{|c|c|c|c|c|}
\hline Motivation factors and items & $\begin{array}{l}\text { Factor } \\
\text { loading }\end{array}$ & $\begin{array}{l}\text { Mean } \\
\text { value }\end{array}$ & $\begin{array}{l}\text { Reliability } \\
\text { coefficient }\end{array}$ & $\begin{array}{l}\text { Average inter-item } \\
\text { correlation }\end{array}$ \\
\hline Factor 1: Knowledge seeking & & 3.42 & 0.89 & 0.54 \\
\hline To learn about endangered species & 0.91 & - & - & - \\
\hline To learn about animals in general & 0.90 & - & - & - \\
\hline To learn about specific animals & 0.88 & - & - & - \\
\hline To learn about plants & 0.76 & - & - & - \\
\hline Primarily for educational reasons (to learn things, increase my knowledge) & 0.65 & - & - & - \\
\hline To photograph animals and plants & 0.40 & - & - & - \\
\hline It is a spiritual experience & 0.31 & - & - & - \\
\hline Factor 2: Park attributes & & 3.72 & 0.80 & 0.45 \\
\hline The park has great accommodation facilities & 0.72 & - & - & - \\
\hline It is an ideal holiday destination & 0.68 & - & - & - \\
\hline It is value for money & 0.65 & - & - & - \\
\hline I am loyal to the park & 0.60 & - & - & - \\
\hline To learn about nature & 0.68 & - & - & - \\
\hline For the benefit of my children & 0.65 & - & - & - \\
\hline $\begin{array}{l}\text { So that other members in my party can develop an appreciation for endangered } \\
\text { species and wildlife }\end{array}$ & 0.60 & - & - & - \\
\hline To be with family or to spend time with someone special & 0.33 & - & - & - \\
\hline Factor 4: Escape & & 4.37 & 0.77 & 0.64 \\
\hline To relax & 0.82 & - & - & - \\
\hline To get away from my normal routine & 0.69 & - & - & - \\
\hline Factor 5: Exploration & & 3.06 & 0.50 & 0.19 \\
\hline To explore a new destination & 0.58 & - & - & - \\
\hline To spend time with friends & 0.48 & - & - & - \\
\hline To see the Big Five & 0.40 & - & - & - \\
\hline To do hiking trails & 0.38 & - & - & - \\
\hline Total variance explained & $63 \%$ & - & - & - \\
\hline
\end{tabular}


it is clear that all three visitor groups travel in groups of three persons, stay in the park for an average of seven to eight nights and that they are motivated mainly by escape, park attributes and group affiliation. The latter finding corresponds to the results of the factor analysis (Table 2).

\section{Cross-tabulations and chi-square test results}

According to Table 5, there are statistically significant differences between first-timers and repeaters at the KNP based on province of origin $(p=0.001)$, WildCard holder status $(p=0.001)$ and decision to visit the park ( $p$ $=0.018)$, whilst accompanying children $(p=0.055)$ and marital status ( $p=0.059)$ were significant at a $10 \%$ level of significance. More first-time visitors and frequent visitors indicated that they travelled with children, compared to very frequent visitors, whilst more repeat visitors (frequent and very frequent) are married and are WildCard holders, compared to first-timers. First-time visitors, on the other hand, plan their trips well in advance, whilst repeaters (frequent and very frequent) plan in advance but also make spontaneous decisions. With regard to province of origin, very frequenters mostly originate from Gauteng and Mpumalanga, whereas first-timers originate from Gauteng and the Western Cape and frequent visitors from Gauteng and KwaZulu-Natal. All three visitor groups also travel from other provinces in South Africa. There were no statistical significant differences based on the other variables. However, it can be seen that all three visitor groups are Afrikaans-speaking with a high level of education, travel to the park in a $4 \times 4$ or sedan and would recommend the park to family and friends.

TABLE 3: Visitors at the Kruger National Park based on frequency of visitation.

\begin{tabular}{lll}
\hline Number of times visited & Count & $\%$ \\
\hline 1 (first time) & 121 & 28 \\
2 and 3 times (frequent visitors) & 194 & 44 \\
4 + times (very frequent visitors) & 121 & 28 \\
\hline
\end{tabular}

\section{Generalisations}

The main findings of this research are as follows: in terms of the factor analysis (reasons for visiting the park), escape was the most important motive for both first-time and repeat visitors to attend the park, which supports general findings in the literature regarding travel motives of visitors to nature-based destinations. Results from the ANOVA support the findings of Gitelson and Crompton (1984), Kruger et al. (2010), Lau and McKercher (2004), Li et al. (2008) and Shani et al. (2009), who indicate that first-time visitors to the KNP are younger than repeat visitors and they pay for fewer people. Therefore, their spending is also lower, which supports the research findings of Shani et al. (2009) and Wang (2004). Although first-timers regarded escape, park attributes and group affiliation as important motives to visit the park, they obtained the lowest mean values on all the factors, compared to repeat visitors. Repeat visitors are mainly motivated by escape and this corresponds to the findings of Gitelson and Crompton (1984), Hughes and Morrison-Saunders (2002) and Kruger et al. (2010), who found that returning visitors seek relaxation. Similar to the findings by Kruger et al. (2010), Li et al. (2008) and Shani et al. (2009), it was found that firsttime visitors travel longer distances to visit the park, whereas repeat visitors are local residents. However, repeat visitors sometimes also travel long distances to visit the park, which support the findings of Shani et al. (2009). First-timers are active travel planners, which supports the findings of $\mathrm{Li}$ et al. (2008). Repeaters usually tend to plan well in advance, but sometimes also make their decisions to visit the park spontaneously. This corresponds with the findings of Kruger et al. (2010). The roles of marital status, accompanying children and being a WildCard holder have not been studied in previous research and indicate that repeat visitors tend to be married and WildCard holders, whilst first-time visitors and frequent visitors tend to travel with children.

This study has the following invaluable implications: firstly, marketers and park management should follow a two-

TABLE 4: Results of analysis of variance and Tukey's post hoc multiple comparisons for Kruger National Park visitor characteristics of first-timers and repeaters.

\begin{tabular}{|c|c|c|c|c|c|}
\hline \multirow[t]{2}{*}{ Characteristics } & \multicolumn{3}{|c|}{ Frequency of park visitation } & \multirow[t]{2}{*}{$F$-ratio } & \multirow{2}{*}{$\begin{array}{c}\text { Significance } \\
\text { level }\end{array}$} \\
\hline & $\begin{array}{l}\text { First time } \\
(N=121)\end{array}$ & $\begin{array}{c}2 \text { and } 3 \text { times } \\
\left(N=\begin{array}{c}194) \text { Frequent } \\
\text { visitors }\end{array}\right.\end{array}$ & $\begin{array}{c}4+\text { times } \\
(N=121) \text { Very frequent } \\
\text { visitors }\end{array}$ & & \\
\hline Age & $42^{\mathrm{a}}$ & $45^{\mathrm{a}}$ & $50^{\mathrm{b}}$ & 10.942 & $0.001^{*}$ \\
\hline Group size & 3 & 3 & 3 & 2.401 & 0.092 \\
\hline Length of stay & & & & 1.009 & 0.365 \\
\hline Nights in KNP & 7 & 8 & 8 & & \\
\hline \multicolumn{6}{|l|}{ Motivations $\dagger$} \\
\hline Knowledge seeking & 3.27 & 3.43 & 3.55 & 2.408 & $0.091 * *$ \\
\hline Park attributes & 3.59 & 3.75 & 3.80 & 2.074 & 0.127 \\
\hline Group affiliation & 3.56 & 3.67 & 3.60 & 0.354 & 0.702 \\
\hline Escape & 4.32 & 4.37 & 4.42 & 0.420 & 0.657 \\
\hline Exploration & 3.21 & 3.97 & 3.05 & 2.634 & $0.073^{* *}$ \\
\hline
\end{tabular}

KNP, Kruger National Park.

$\dagger$, Respondents were asked to indicate how they evaluate each motivation item on the scale $(1=$ not at all important; $2=$ less important; $3=$ neither important nor less important;

$4=$ very important; $5=$ extremely important).

a, Group differs significantly from type (in row) where ${ }^{b}$, is indicated.

*, Statistically significant difference: $5 \%$ level

$* *$, Statistically significant difference: $10 \%$ leve 
pronged approach that caters for the needs of both markets, as proposed by Kruger et al. (2010). This is vital, since these markets are important, and a continuous flow of first-timers would ensure the sustainability of the KNP. First-time visitors are furthermore younger and they are a potential long-term market that should be converted into repeat visitors. Thus, as pointed out by Lau and McKercher (2004) and Oppermann (1997), the KNP should aim to achieve a balance between first-time and repeat visitors. According to the results it does appear that there is a balance. Follow-up studies need to be conducted to confirm or deny this observation. In this regard, the WildCard (loyalty card) seems to be an effective tool to increase visitation, thereby creating repeaters. In order to retain first-timers, it seems that activities aimed at children would increase the possibility of return visits. Childrens' activities could include interpretation and education centres,

TABLE 5: Chi-square test results of visitor characteristics of first-time and repeat Kruger National Park visitors.

\begin{tabular}{|c|c|c|c|c|c|c|c|}
\hline \multirow[t]{2}{*}{ Characteristics } & \multicolumn{3}{|c|}{ Frequency of participation } & \multirow[t]{2}{*}{ Chi-square value } & \multirow[t]{2}{*}{ DF } & \multirow[t]{2}{*}{ Significance level } & \multirow[t]{2}{*}{ Phi-value } \\
\hline & $\begin{array}{l}\text { First-time visitors } \\
\qquad(N=121)\end{array}$ & $\begin{array}{l}\text { Frequent visitors } \\
2-3 \text { times } \\
(N=194)\end{array}$ & $\begin{array}{l}\text { Very frequent } \\
\text { visitors } 4+\text { times } \\
(N=121)\end{array}$ & & & & \\
\hline Home language & & & & 5.752 & 4 & 0.218 & 0.115 \\
\hline English & $40 \%$ & $38 \%$ & $38 \%$ & - & - & - & - \\
\hline Afrikaans & $48 \%$ & $56 \%$ & $51 \%$ & - & - & - & - \\
\hline Other (foreign) & $12 \%$ & $6 \%$ & $12 \%$ & - & - & - & - \\
\hline Accompanying children & & & & 9.266 & 7 & $0.055^{* *}$ & 0.147 \\
\hline Yes & $50 \%$ & $57 \%$ & $41 \%$ & - & - & - & - \\
\hline No & $50 \%$ & $43 \%$ & $59 \%$ & - & - & - & - \\
\hline Province & & & & 41.152 & 16 & $0.001^{*}$ & 0.326 \\
\hline Gauteng & $58 \%$ & $62 \%$ & $53 \%$ & - & - & - & - \\
\hline KwaZulu-Natal & $9 \%$ & $9 \%$ & $2 \%$ & - & - & - & - \\
\hline Eastern Cape & $2 \%$ & $2 \%$ & $3 \%$ & - & - & - & - \\
\hline Western Cape & $13 \%$ & $8 \%$ & $4 \%$ & - & - & - & - \\
\hline Northern Cape & $0 \%$ & $2 \%$ & $1 \%$ & - & - & - & - \\
\hline Limpopo & $7 \%$ & $4 \%$ & $8 \%$ & - & - & - & - \\
\hline Mpumalanga & $7 \%$ & $8 \%$ & $28 \%$ & - & - & - & - \\
\hline Free State & $2 \%$ & $2 \%$ & $1 \%$ & - & - & - & - \\
\hline North West & $3 \%$ & $3 \%$ & $2 \%$ & - & - & - & - \\
\hline Marital status & & & & 14.987 & 8 & $0.059 * *$ & 0.186 \\
\hline Married & $71 \%$ & $71 \%$ & $76 \%$ & - & - & - & - \\
\hline Not married & $21 \%$ & $14 \%$ & $11 \%$ & - & - & - & - \\
\hline Divorced & $5 \%$ & $4 \%$ & $2 \%$ & - & - & - & - \\
\hline Widowed & $2 \%$ & $1 \%$ & $2 \%$ & - & - & - & - \\
\hline Living together & $2 \%$ & $10 \%$ & $11 \%$ & - & - & - & - \\
\hline Level of education & & & & 13.049 & 10 & 0.221 & 0.175 \\
\hline No school & $0 \%$ & $0 \%$ & $2 \%$ & - & - & - & - \\
\hline Matric & $23 \%$ & $23 \%$ & $25 \%$ & - & - & - & - \\
\hline Diploma or degree & $42 \%$ & $37 \%$ & $39 \%$ & - & - & - & - \\
\hline Postgraduate & $17 \%$ & $17 \%$ & $15 \%$ & - & - & - & - \\
\hline $\begin{array}{l}\text { Professional } \\
\text { Other }\end{array}$ & $\begin{array}{l}14 \% \\
4 \%\end{array}$ & $\begin{array}{l}21 \% \\
2 \%\end{array}$ & $\begin{array}{l}19 \% \\
0 \%\end{array}$ & - & - & - & - \\
\hline Type of transport & & & & 6.682 & 10 & 0.755 & 0.124 \\
\hline $4 \times 4$ & $32 \%$ & $31 \%$ & $38 \%$ & - & - & - & - \\
\hline Kombi & $10 \%$ & $11 \%$ & $9 \%$ & - & - & - & - \\
\hline Leisure vehicle & $10 \%$ & $9 \%$ & $9 \%$ & - & - & - & - \\
\hline Sedan & $27 \%$ & $25 \%$ & $25 \%$ & - & - & - & - \\
\hline $2 \times 4$ or Bakkie & $18 \%$ & $21 \%$ & $19 \%$ & - & - & - & - \\
\hline Other & $4 \%$ & $3 \%$ & $4 \%$ & - & - & - & - \\
\hline WildCard holder & & & & 23.184 & 2 & $0.001^{*}$ & 0.231 \\
\hline Yes & $63 \%$ & $83 \%$ & $86 \%$ & - & - & - & - \\
\hline No & $37 \%$ & $17 \%$ & $14 \%$ & - & - & - & - \\
\hline Recommend the park & & & & 0.180 & 2 & 0.914 & 0.020 \\
\hline Yes & $98 \%$ & $98 \%$ & $98 \%$ & - & - & - & - \\
\hline No & $2 \%$ & $2 \%$ & $2 \%$ & - & - & - & - \\
\hline Decision to visit the park & & & & 15.364 & 6 & $0.018^{*}$ & 0.189 \\
\hline Spontaneous decision & $8 \%$ & $14 \%$ & $13 \%$ & - & - & - & - \\
\hline Less than a month ago & $8 \%$ & $6 \%$ & $12 \%$ & - & - & - & - \\
\hline More than a month ago & $60 \%$ & $53 \%$ & $39 \%$ & - & - & - & - \\
\hline Other & $24 \%$ & $27 \%$ & $36 \%$ & - & - & - & - \\
\hline
\end{tabular}

*, Statistically significant difference: $5 \%$ level

${ }^{* *}$, Statistically significant difference: $10 \%$ level 
playgrounds and game drives with guides, to name a few. Moreover, the KNP should take into account the differences between first-time and repeat visitors and develop different marketing strategies and programmes for these two potentially different market segments (Vogt et al. 1998:69; Wang 2004:115).

Secondly, marketing messages should incorporate the travel motives escape, park attractiveness and group affiliation to attract both first-time and repeat visitors as these aspects seem to be the main reasons why people visit the KNP.

Thirdly, both first-timers and repeaters plan their park visits well in advance and therefore gather information extensively. Repeat visitors also tend to make their decision to visit spontaneously and this implies that marketing should be done on a continuous basis to attract both visitor segments. Therefore, it would be advisable to use a wide range of marketing tools such as magazines, newspapers, radio, television advertisements and billboards.

\section{Summary and conclusion}

The purpose of this study was to distinguish between firsttime and repeat visitors to the KNP, based on frequency of visitation. It was the first time that this approach was used at a nature-based destination in South Africa. This innovative approach contributes to the body of knowledge on the viability of park visitors by applying a segmentation technique that enables the identification of differences according the visitors' purchasing behaviour. Statistically significant differences were found between first-time and repeat visitors, based on socio-demographic and behavioural characteristics as well as reasons for visiting the park. The results both supported and contradicted previous research, as discussed in the literature review and the section dealing with the findings of this research. This research especially verifies the notion that the unique nature of each tourism product or destination plays a vital role in the type of visitors attracted to these destinations. This means that first-time and repeat visitors cannot be regarded as homogeneous in terms of their profiles, motives, preferences and consequent behaviour. The study also showed that a combination of first-timers and repeat visitors would contribute to a more sustainable and competitive park. It is recommended that this approach be applied at other nature-based destinations or products in order to overcome one of the major limitations of this type of research, namely a lack of comparative studies.

\section{Acknowledgements}

The authors gratefully acknowledge the National Research Foundation (NRF) as well as SANParks for financial assistance. They are also thankful to all the fieldworkers for distributing the questionnaires as well as all the respondents who were willing to participate in the survey.

\section{Competing interests}

The authors declare that they have no financial or personal relationship(s) that may have inappropriately influenced them in writing this article.

\section{Authors' contributions}

M.K. (North-West University) was the lead author on the article, conceptualised the idea, conducted the survey, analysed the data together with the Statistical Consultation Services at North-West University and did the final technical editing. M.S. (North-West University) focused on the findings and implications as well as the general flow of the research, whilst U.P.H. (Tswane University of Technology) assisted with the literature review.

\section{References}

Alegre, J. \& Juaneda, C., 2006, 'Destination loyalty: Consumers' economic behaviour', Annals of Tourism Research 33(3), 684-706. http://dx.doi.org/10.1016/j annals.2006.03.014

Chiang, D., Wang, Y. \& Chen, S., 2010, 'Analysis on repeat buying patterns', Knowledgebased Systems 23(8), 757-768. http://dx.doi.org/10.1016/j.knosys.2010.04.012

Clark, L.A. \& Watson, D., 1995, 'Constructing validity: basic issues in objective scale development', Psychological Assessment 7(3), 309-319. http://dx.doi. org/10.1037/1040-3590.7.3.309

Cook, R.A., Yale, L.J. \& Marqua, J.J., 2010, Tourism. The business of travel, 4th edn., Pearson Education Inc., Upper Saddle River, NJ.

Correia, A., Oliveira, N. \& Butler, R., 2008, 'First-time and repeat visitors to Cape Verde: The overall image', Tourism Economics 14(1), 185-203. http://dx.doi. org/10.5367/000000008783554848

Crompton, J.L., Fakeye, P.C. \& Lue, C.C., 1992, 'Positioning: The example of the Lower Rio Grande Valley in the winter long stay destination market', Journal of Travel Research 31(2), 20-26. http://dx.doi.org/10.1177/004728759203100204

Downward, P. \& Lumsdon, L., 2004, 'Tourism transport and visitor spending: A study in the North York Moors National Park, UK', Journal of Travel Research 42(4), 415420. http://dx.doi.org/10.1177/0047287504263038

Fakeye, P.C. \& Crompton, J.L., 1991, Image differences between prospective, first-time, and repeat visitors to the lower Rio Grande Valley', Journal of Travel Research 30(2), 10-16. http://dx.doi.org/10.1177/004728759103000202

Field, A., 2005, Discovering statistics using SPSS, 2nd edn., SAGE Publications, London,Thousand Oaks, CA.

Formica, S. \& Uysal, M., 1995, 'A market segmentation of festival visitors: Umbria Jazz Festival in Italy', Festival Management and Event Tourism 3(4), 175-182. http:// dx.doi.org/10.3727/106527095792232523

Gitelson, R.J. \& Crompton, J.L., 1984, 'Insights into the repeat vacation phenomenon' Annals of Tourism Research (2), 199-217. http://dx.doi.org/10.1016/01607383(84)90070-7

Hellier, P.K, Guersen, G.M., Carr, R.A. \& Rickard, J.A., 2003, 'Customer repurchase intention: A general structural equation model', European Journal of Marketing 37(11/12), 1762-1800. http://dx.doi.org/10.1108/03090560310495456

Hong, S., Lee, S.W., Lee, S. \& Jang, H., 2009, 'Selecting revisited destinations', Annals of Tourism Research 36(2), 268-294. http://dx.doi.org/10.1016/j. annals.2009.01.001

Hughes, M. \& Morrison-Saunders, A., 2002, 'Repeat and first time visitation in an experience specific context: The valley of the giants tree top walk', Journal of Tourism Studies 13(1), 20-25.

Israel, G.D., 2009, Determining sample size, viewed 12 May 2010, from http://www. edis.ifas.ufl.edu/pdffiles/pd/pd00600.pdf

Jang, S. \& Feng, R., 2007, 'Temporal destination revisit intention: the effects of novelty seeking and satisfaction', Tourism Management 28(2), 580-590. http://dx.doi. org/10.1016/j.tourman.2006.04.024

Juaneda, C., 1996, 'Estimating the probability of return visits using a survey: Tourists' expenditure in the Balearic Islands', Tourism Economics 2(4), 339-352.

Kerstetter, D. \& Cho, M.H., 2004, 'Prior knowledge, credibility and information search', Annals of Tourism Research 31(4), 961-985. http://dx.doi.org/10.1016/j. annals.2004.04.002

Kotler, P., Bowen, J. \& Makens, J., 2003, Marketing for hospitality and tourism, international edn., Pearson Education, Upper Saddle River, NJ.

Kruger, M., Erasmus, J., Du Plessis, L. \& Saayman, M., 2010, A marketing analysis of overnight and day visitors to Kruger National Park December 2009/10, Institute for Tourism and Leisure Studies, North-West University, Potchefstroom.

Kruger, M. \& Saayman, M., 2009, 'Travel motives of visitors attending Oppikoppi Music Festival', Acta Academica 41(4), 56-73.

Kruger, M. \& Saayman, M., 2010, 'Travel motivation of tourists to Kruger and Tsitsikamma National Parks: A comparative study', South African Journal of Wildlife Research 40(1), 93-102. http://dx.doi.org/10.3957/056.040.0106

Kruger, M., Saayman, M. \& Ellis, S., 2010, 'Does loyalty pay? First-time versus repeat visitors at a national arts festival', South African Business Review 14(1), 79-104.

Kumar, D. \& Shah, D., 2004, 'Building and sustaining profitable customer loyalty for the 21st century', Journal of Retailing 80(4), 317-330. http://dx.doi.org/10.1016/j. jretai.2004.10.007 
Lau, A.L. \& Mckercher, B., 2004, 'Exploration versus acquisition: a comparison of firsttime and repeat visitors' Journal of Travel Research 42(1), 279-285. http://dx.doi. time and repeat visitors', Journal of

Lehto, X.Y., O'Leary, J.T. \& Morrison, A.M., 2004, 'The effect of prior experience on vacation behaviour', Annals of Tourism Research 31(4), 801-818. http://dx.doi. org/10.1016/j.annals.2004.02.006

Leones, J., Colby, B. \& Crandall, K., 1998, 'Tracking expenditures of the elusive nature tourists of south-eastern Arizona', Journal of Travel Research 36(3), 56-64. http:// dx.doi.org/10.1177/004728759803600306

Li, X., Cheng, C., Kim, H. \& Petrick, J.F., 2008, 'A systematic comparison of first-time and repeat visitors via a two-phase online survey', Tourism Management 29(2), 278-293. http://dx.doi.org/10.1016/j.tourman.2007.03.010

Mabunda, D.M. \& Wilson, D., 2009, 'Commercialisation of National Parks: South Africa's Kruger National Park as an example, in J. Saarinen, F. Becker, H. Manwa \& D. Wilson (eds.), Sustainable tourism in Southern Africa, pp. 116-133, Channel View Publications, Bristol, UK.

McCain, S.C., Jang, S. \& Hu, C., 2005, 'Service quality gap analysis toward customer loyalty: Practical guidelines for casino hotels', International Journal of Hospitality Management 24(3), 465-472. http://dx.doi.org/10.1016/j.ijhm.2004.09.005

McKercher, B. \& Wong, D.Y.Y., 2004, 'Understanding tourism behaviour: examining the combined effects of prior visitation history and destination status', Journal of Travel Research 43(2), 171-179. http://dx.doi.org/10.1177/0047287504268246

Mehmetoglu, M., 2007, 'Typologising nature-based tourists by activity - Theoretical and practical implications', Tourism Management 28(3), 651-660. http://dx.doi. org/10.1016/j.tourman.2006.02.006

Morais, D.B. \& Lin, C.H., 2010, 'Why do first-time and repeat visitors patronize a destination?' Journal of Travel and Tourism Marketing 27(1), 193-21 http:// dx.doi.org/10.1080/105484010035904430.

Opperman, N.M., 1997, 'First-time and repeat tourists to New Zealand' Tourism Management 18(3), 177-181. http://dx.doi.org/10.1016/S0261 5177(96)00119-7

Oppermann, M., 1998, 'Destination thresholds potential and the law of repeat visitation', Journal of Travel Research 37(2), 131-137. http://dx.doi. org/10.1177/004728759803700204

Oppermann, M., 1999, 'Predicting destination choice: A discussion of destination loyalty', Journal of Vacation Marketing 5(1), 51-65. http://dx.doi. org/10.1177/135676679900500105

Oppermann, M., 2000, 'Tourism destination loyalty', Journal of Travel Research 39(1), 78-84. http://dx.doi.org/10.1177/004728750003900110

Pallant, J., 2007, SPSS Survival Manual: A Step-by-step Guide to Data Analysis using SPSS Version 15, 3rd edn., McGraw-Hill, New York, NY.

Petrick, J.F., 2004, 'Are loyal visitors the desired visitors?', Tourism Management 25(1) 463-470. http://dx.doi.org/10.1016/S0261-5177(03)00116-X

Petrick, J.F. \& Backman, S.J., 2001, 'An examination of golf travellers' satisfaction, perceived value and loyalty and intentions to revisit', Journal of Travel Research 6(3/4), 223-237.
Petrick, J.F., Morais, D. \& Norman, W., 2001, 'An examination of the determinants of entertainment vacationers' intentions to visit', Journal of Travel Research 40(1), 41-48. http://dx.doi.org/10.1177/004728750104000106

Priestly, G. \& Mundet, L., 1998, 'The post-stagnation phase of the resort cycle', Annals of Tourism Research 25(1), 85-111. http://dx.doi.org/10.1016/S01607383(97)00062-5

Reid, L.J. \& Reid, S.D., 1993, 'Communicating tourism suppliers services: Building repeat visitor relationships', Journal of Travel and Tourism Marketing 2(2/3), 3-20.

Saayman, M., 2003, 'A marketing analysis of tourist visiting Kgalagadi Transfrontier and Augrabies Falls National Parks in South Africa', unpublished report delivered for the South African Nation
Potchefstroom, South Africa.

Saayman, M. \& Saayman, A., 2009, 'Creating a framework to determine the socioeconomic impact of national parks in South Africa: Case study of the Addo Elephant National Park', Koedoe 51(1), 49-57.

Saayman, M. \& Van Der Merwe, P., 2004, Managing game farms from a tourism perspective, 2nd edn., Institute for Tourism and Leisure Studies, Potchefstroom.

SANParks, 2009, National Parks report, viewed 15 February 2010, from http://www. sanparks.org/about/annual/2009.pdf

SANParks, 2010, Annual Report 2009/2010, viewed 20 February 2012, from http:// sanparks.org.za/docs/general/annual-report-2010.pdf

Shani, A., Rivera, M.A. \& Hara, T., 2009, 'Assessing the viability of repeat visitors to cultural events: evidence from the Zora! Festival', Journal of Convention and Event Tourism 10(1), 89-104. http://dx.doi.org/10.1080/15470140902946378

Shanka, T. \& Taylor, R., 2004, 'Discriminating factors of first-time and repeat visitors to wine festivals', Current Issues in Tourism 7(2), 134-145. http://dx.doi. org/10.1080/13683500408667976

SPSS ${ }^{\circledR} 16.0$ for Windows, 2010, computer software, SPSS Inc., Chicago, IL.

Steyn, H.S., 2000, 'Practical significance of the difference in means', South African Journal of Industrial Psychology 26(3), 1-3.

Tang, Q. \& Turco, D.M., 2001, 'Spending behaviours of event tourists', Journal of Convention and Exhibition Marketing 3(2), 33-40. http://dx.doi.org/10.1300/ J143v03n02 04

Tideswell, C. \& Faulkner, B., 1999, 'Multidestination travel patterns of international visitors to Queensland', Journal of Travel Research 37(4), 364-374. http://dx.doi. org/10.1177/004728759903700406

Um, S., Chon, K. \& Ro, Y., 2006, 'Antecedents of revisit intention', Annals of Tourism Research 33(4), 1141-1158. http://dx.doi.org/10.1016/j.annals.2006.06.003

Uysal, M., McDonald, C.D. \& Martin, B.S., 1994, 'Australian visitors to US national parks and natural areas', International Journal of Contemporary Hospitality Management 6(3), 18-24. http://dx.doi.org/10.1108/09596119410059209

Vogt, C.A., Stewart, S.I. \& Fesenmaier, D.R., 1998, 'Communication strategies to reach first-time visitors', Journal of Travel and Tourism Marketing 7(2), 69-89. http:// dx.doi.org/10.1300/J073v07n02_04

Wang, D., 2004, 'Tourist behaviour and repeat visitation to Hong Kong', Tourism Geography 6(1), 99-118. 